
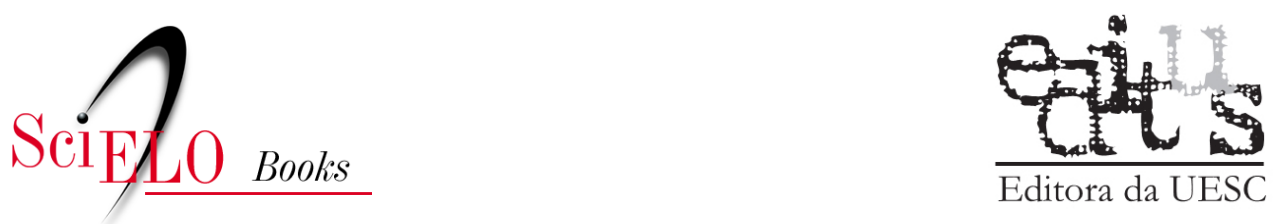

\title{
Parte 1 - Migração e gênero Histórias e geografias sem fronteiras? Migrações, gênero e (in)tolerâncias entre Brasil, Portugal e Espanha
}

\author{
Vanessa Ribeiro Simon Cavalcanti \\ Antonio Carlos da Silva
}

\section{SciELO Books / SciELO Livros / SciELO Libros}

CAVALCANTI, V. R. S., and SILVA, A. C. Histórias e geografias sem fronteiras? Migrações, gênero e (in)tolerâncias entre Brasil, Portugal e Espanha. In: SANTOS, M. L., ANUNCIAÇÃO, C. S., and CAVALCANTI, V., eds. Migrações e identidades: várias óticas e perspectivas [online]. Ilhéus, BA: EDITUS, 2017, pp. 15-48. ISBN: 97885-7455-492-1. https://doi.org/10.7476/9788574554921.0001.

\section{(c) $\underset{\mathrm{EY}}{\mathrm{B}}$}

All the contents of this work, except where otherwise noted, is licensed under a Creative Commons Attribution 4.0 International license.

Todo o conteúdo deste trabalho, exceto quando houver ressalva, é publicado sob a licença Creative Commons Atribição 4.0.

Todo el contenido de esta obra, excepto donde se indique lo contrario, está bajo licencia de la licencia Creative Commons Reconocimento 4.0. 


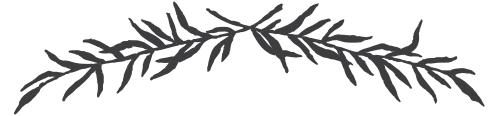 \\ HISTÓRIAS E GEOGRAFIAS SEM FRONTEIRAS? MIGRAÇÓES, GÊNERO E (IN)TOLERÂNCIAS ENTRE BRASIL, PORTUGAL E ESPANHA $^{1}$
}

\author{
Vanessa Ribeiro Simon Cavalcanti, \\ Universidade Católica do Salvador, Brasil ${ }^{2}$ \\ Antonio Carlos da Silva, \\ Universidade Católica do Salvador, Brasil ${ }^{3}$
}

De todas as partes llegan, en cualquier lugar trabajan, bajo el más frondoso de los árboles sufren, se entregan, cobran y pagan, que son ellas, las esclavas, las que mantienen el negocio más vil de este pais (España) que va tan bien.

1 Texto embasado em artigo ROTAS ENTRE BRASIL E PENÍNSULA IBÉRICA: Linhas cruzadas nos processos migratórios femininos publicado nos Anais do XIX Encontro Regional de História: Poder, Violência e Exclusão. ANPUH/SP-USP. São Paulo, 8 a 12 de setembro de 2008. Cd-Rom em parceria com Claudia Eleutério Felipe dos Santos.

2 Historiadora. Pós-doutora pela Universidade de Salamanca, Espanha (CAPES e CNPq). Doutora em História - Universidad de Leon, Espanha. Professora do Programa de Pós-Graduação em Família na Sociedade Contemporânea (UCSAL). Professora visitante do Centro de Estudos Brasileiros da Universidade de Salamanca. Integrante do NPEJI/UCSAL e do Núcleo de Estudos de História Social da Cidade - NEHSC PUC/SP. Coordenadora do Grupo de Criação e Difusão do conhecimento sobre Movimentos sociais, migraçóes e políticas públicas do Centro de Estudios Brasileños (CEB/ USAL) da Universidade de Salamanca.E-mail: <vanessa.cavalcanti@uol.com.br>

3 Economista. Pós-doutor pela Universidade de Coimbra, Centro de Estudos Sociais, Portugal. Doutor pela Universidade de Leon, Espanha. Professor do Programa de Pós-Graduação em Políticas Sociais e Cidadania da Universidade Católica do Salvador (UCSAL). Professor visitante de Economia no Centro de Estudos Brasileiros da Universidade de Salamanca. Integrante do Núcleo de Estudos sobre Instituiçốes e Governação (NEIG/UCSAL). Assessor de Relações Internacionais da Universidade Católica do Salvador (UCSAL).E-mail:<carlos.zamora@uol.com.br>. 
Alfonso Ussia, de El Lago de la Carne, 2001.

"Meu sonho era fazer a vida e poder ajudar minha familia... meu pesadelo foi conhecer um outro lado do sonho de chegar na Espanha e sair da situação que me encontrava na minha cidade, interior da Babia".

M.S.S., 19 anos, prostituta em Ciudad Rodrigo desde 2009.

\section{Definindo as fronteiras}

Movimentos migratórios são característicos das sociedades desde que estas existem e se configuram como tal. Com o distanciamento cada vez maior, na atualidade, entre países desenvolvidos e países cujas condiçôes sociais e Índices de Desenvolvimento $\mathrm{Hu}$ mano (IDH) são baixos, os processos migratórios são mais intensos. A via de mão dupla existe somente em algumas zonas e regióes extremamente reguladas e com aparatos legais e jurídicos que permitem um controle social e estatístico mais estável.

$\mathrm{O}$ fenômeno migratório tem ganhado inclusive espaços cotidianos nos mass media e sido colocado como prioridade na agenda internacional de Direitos Humanos e Relaçóes Internacionais. Sua historicidade mais recente pode ser confirmada pela intensificação de deslocamentos e circulação de pessoas ocorrida pós-II Guerra Mundial, seja resultante de guerras e conflitos entre povos, catástrofes naturais ("refugiados ou migrantes ambientais") ou por motivos laborais. O sentido Sul-Norte também já não limita os estudos e as relaçóes mais tensas, consolidando outros movimentos e tendências na mobilidade, alterando os perfis migratórios e abrindo uma "brecha" para investigaçóes, agendas e açóes. Aliás, isso impulsiona novas abordagens não mais centradas exclusivamente nos aspectos laborais e "passam a representar uma rede muito mais complexa de circulação de pessoas, assente em factores como a migração econômica, de consumo e de talento" (MATIAS, 2014, p. 10). 
A circulação massiva de pessoas e mercadorias tomou assento em uma nova onda migratória a partir dos anos 90, mas as fronteiras não somente são alfandegárias e de controle: transformaram-se em símbolos e elementos do impossível, mas também ganharam status de lugares de passagem e de transformação. Tal processo intensifica, nos últimos anos, a migração legal, refugiada, por agrupamentos familiares e/ou transnacionalização das famílias etc e traz abordagens e problemáticas da História do Tempo Presente.

Podem-se marcar como pontos cruciais a influência mútua das identidades (aqui não fazendo nenhuma vinculação com a categoria do multiculturalismo), individuais e coletivas, assinalando paradoxos e idiossincrasias de uma sociedade internacional que promove, mas, ao mesmo tempo, viola direitos humanos e agendas ratificadas. As noçóes de eu e outros, de alteridade e de solidariedade e liberdade são colocadas em xeque, exigindo novos olhares e novas agendas que contemplem desejos individuais e acordos coletivos. Entretanto, a marcação de "fronteiras" serve não mais para nos deter, mas para que possamos exercer essa livre passagem para o outro salientar a maravilha do aqui-lá parece mais, na atualidade, algo que está no campo ideal.

Nunca nos assombramos tanto com o "fantasma que ronda a Europa",

perigosa montanha confrontando a humanidade é a totalidade combinada de determinaçôes estruturais do capital que deve ser conquistada em todas as suas dimensóes profundamente integradas. É claro que o Estado é um componente vital nesse conjunto de inter-relaçóes, tendo em vista o seu papel direto e, agora, avassalador na modalidade necessária de tomada de decisão global (MÉSZÁROS, 2015, p. 29).

Manuel Castells, em Observatório Global (2006), afirma que a globalização nâo pode ser restrita somente ao deslocamento 
de empresas e fluxos de capitais. Grandes fluxos migratórios a partir da pobreza e, sobretudo, da esperança de um futuro melhor para seus filhos suscitam o espírito empreendedor migratório e fazem com que América Latina, África e Ásia se convertam, junto com o Leste Europeu, em fonte contínua de pessoas que buscam, nas zonas ricas da Europa e América, as oportunidades de vida e de trabalho que não são oferecidas em seus países de origem.

No entanto, a busca por condiçôes melhores e possibilidades de estabilidade fazem dos imigrantes uma massa numerosa e ávida por ultrapassar fronteiras (sejam elas econômicas, sociais ou políticas, no caso de exilados e refugiados).

Partindo da esfera individual e pessoal, a temática também traz a necessidade de ampliar responsabilidades e sujeitos envolvidos, sejam famílias, sociedade, mercado e Estado. Este último, com demarcação de suas responsabilidades - no âmbito nacional ou internacional - almeja promover o desenvolvimento através de um exercício de estratégia em favor da redução das disparidades sociais associada ao recrudescimento da economia em seu tripé de sustentação: emprego, renda e produção (SILVA, 2008).

Sob a orientação da Teoria Crítica (dissociação-valor e fetiche da mercadoria), é proeminente enfatizar que a forma social está subordinada ao processo de valorizaçáo do capital, o sujeito automático da sociedade, não necessariamente com substância. As relaçôes sociais, por conseguinte, são heteronômicas e representadas simbolicamente na forma dinheiro. Ou seja, "somente esta lógica fez da produção de mercadorias e, com isto, do mercado, um sistema universal de dominaçáo social" (KURZ, 2015, p. 54).

A orientação migratória contemporânea, em alteridade com os surtos de modernização característicos do século XVIII ao final do século XX, é consequência do atual estágio da crise estrutural do capital, no qual mais seres humanos são reconhecidos como superflúos para os critérios de rentabilidade e produção. O suplantar da barbárie em detrimento da humanização: 
É verdade que o universalismo ocidental sugere o reconhecimento irrestrito de todos os indivíduos, em igual medida, como 'seres humanos em geral', dotados dos célebres 'direitos inalienáveis'. Ao mesmo tempo, é o mercado universal que forma o fundamento de todos os direitos, incluindo os direitos humanos elementares. Temos de lidar com uma relação paradoxal: reconhecimento por meio do năo-reconhecimento, ou, inversamente, não-reconhecimento justamente por meio do reconhecimento. A aparente contradição se dissolve se perguntamos pela definição de ser humano que subjaz a esse paradoxo. A primeira fórmula dessa definição reza: "O ser humano" é em princípio um ser solvente (...) Mas, se entendermos a definição de ser humano como uma relaçáo social (...) a capacidade de entrar numa relação jurídica está ligada, portanto, à capacidade de participar de alguma maneira no processo de valorização do capital. Conforme essa definição, o ser humano tem de ser capaz de trabalhar, ele precisa vender a si mesmo ou alguma coisa (em caso de necessidade, os próprios órgãos do corpo), sua existência deve satisfazer o critério da rentabilidade. Esse é o pressuposto tácito dos direitos humanos (KURZ, 2003, p. 1, grifo do autor).

A elaboração teórica, neste contexto, torna possível reelaborar o passado para compreensão do presente e engendrar outro devir histórico. Se a nova migração global apresenta estruturas próprias, não há como negar que estão sob os auspícios de um fluxo socioeconômico de pessoas oriundas de regióes excluídas do processo de valorização do capital às áreas de rentabilidade (ainda que efêmeras e sujeitas ao horizonte incerto de crescimento econômico sustentável). 


\title{
Portos, aeroportos, estaçóes...: lugares de chegadas, mas também de despedidas
}

\author{
Todos os dias é um vai-e-vem \\ A vida se repete na estação \\ Tem gente que chega pra ficar \\ Tem gente que vai pra nunca mais \\ Tem gente que vem e quer voltar \\ Tem gente que vai e quer ficar \\ Tem gente que veio só olhar \\ Tem gente a sorrir e a chorar \\ E assim, chegar e partir.
}

\section{Milton Nascimento e Fernando Brant}

Chegadas e partidas. Ao longo da história humana, uma de suas expressōes, sem dúvida, é o processo migratório. Ir e vir, ir, voltar e retornar, açóes comuns e que marcam todo o processo relacional e civilizatório, mas também matizado por violências, injustiças, tráfico e exploração de pessoas, busca por integração e inserção (seja laboral, cultural e até afetiva). É a faculdade de transformar em espaços de esperança nossos espaços de sofrimento ou de fracassos, mesmo que seja extremamente fácil nos colocarmos no lugar daqueles que sofrem realmente o fracasso e a tristeza. Tal representação permite transpor a fronteira dos lugares onde outros seres humanos sofrem e perduram. Nem toda emigraçáo ou imigração é desejada e realizada em seu esplendor.

É porque os Portos, negreiros ou não, nos emocionam tanto: e também as grutas e cavernas, as celas, as distâncias e os doentes incuráveis, os lugares em que você sofre e os lugares que você ignora, os incalculáveis e os excepcionais, Auschwitz e o incomunicável, (...) os vulcóes das Américas, Rapa Nui [Ilha de Páscoa] no centro do inconcebível, Matouba em cinzas, a plantation encouraçada de cana-de-açúcar, Cartago e o sal negro, o ventre dos navios negreiros, os tributos e o sal vermelho, 
Hiroshima e Nagasaki, a Grande Muralha tão grande para se atingir e para acabar, a cela de Sócrates, a biblioteca de Tombouctou, Nova Orleans e seus Katrinas desde sempre, os pesticidas que contaminam as bananas, o vulcáo de Empedocle, as favelas que se amontoam umas sobre as outras em todo o mundo, o caminho no fogo do Saara e dos desertos do Leste, Circe no abismo tenebroso do esquecimento, Lisboa e São Francisco e seus tremores, a Atlântida, Bagdá, o Styx, e para mim a agonia do rio Lézarde (GLISSANT, 2008, p. 8).

E se a esfera social responsável por interceder e regulamentar o mercado (imposição de limites), o Estado, encontra-se em profunda crise, o seu espaço de atuação é nacional e as relaçóes econômicas são determinantes mundiais, continuar a apostar na reforma política como ação transformadora é, no mínimo, a confirmação de um paradoxo que náo desafia os limites internos do sistema de reprodução social do capital, tampouco propóe uma radical crítica que atenda às reais necessidades imediatas.

De qualquer modo, a ideologia dominante hoje em dia define que, quanto mais as pessoas estiverem submetidas a contextos objetivos em relação aos quais são impotentes, ou acreditam ser impotentes, tanto mais elas tornarão subjetiva esta impotência. Conforme o ditado de que tudo depende unicamente das pessoas, atribuem às pessoas tudo o que depende das condiçôes objetivas, de tal modo que as condiçóes existentes permanecem intocadas (ADORNO, 2003, p. 36).

O caráter universal da migração, reiteramos, é uma consequência do esgotamento do mecanismo de compensação do mercado de trabalho, a confirmação histórica de que a racionalização eliminadora de trabalho supera a expansão dos mercados. Uma globalização negativa em que o Estado apresenta-se incapaz de financiar o nível civilizatório da modernidade. 
Na periferia mundial, o processo é ainda pior porque a base social de reprodução capitalista não pode ser turbinada com a microeletrônica, por falta de capital suficiente. Não há condiçóes de o capital absorver mão de obra. Isso representa um novo conceito cínico de desenvolvimento. $\mathrm{O}$ antigo sempre se relacionava a um país inteiro, a uma economia nacional. Hoje, o novo conceito se baseia nas áreas pequenas. É a produção desse oásis que garante a economia. Para o resto, há apenas o gerenciamento de crises (KURZ apud MASSAD, 2009, p. 1).

Contudo, à luz da teoria da dissociação-valor, são as mulheres as principais referências deste "reconhecimento pelo não reconhecimento". Desapropriadas de sua razão de ser, passam a incorporar as fileiras de reprodução social do capital, sempre no sentido de externalização dos custos inseridos, da alienação sob a forma de dinheiro em suas vertentes mais indeléveis de coisificação do ser humano.

\section{Passagens que revelam destinos: mulheres brasileiras em Espanha ${ }^{4}$}

Eu estou indo, eu estou indo, mas não sei se volto! Testemunho para a PESTRAF de mulher

4 Este item contou com a participação de Claudia Eleutério Filipe dos Santos (UNEB) e Ana Manuela Santos Conceição (UCSAL), estudantes de Mestrado e Iniciação Científica, respectivamente, e integrantes do Núcleo de Estudos e Pesquisas sobre Juventude e Identidades, e orientadas por Vanessa Cavalcanti. Dentro da produção já publicada e divulgada, por conta do desenvolvimento de pesquisas financiadas pela FAPESB, ambas apresentaram trabalhos em eventos científicos. Ver CAVALCANTI, Vanessa Ribeiro Simon \& SANTOS, Cláudia Eleutério Felipe dos. Rotas entre Brasil e Península Ibérica: Linhas cruzadas nos processos migratórios femininos. Texto integrante dos Anais do XIX Encontro Regional de História: Poder, Violência e Exclusão. ANPUH/SP-USP. São Paulo, 2008; e CAVALCANTI, Vanessa Ribeiro Simon \& SANTOS CONCEIÇĀO, Ana Manuela. Brasileiras em Portugal no processo migratório e de exploração sexual. CienteFico.com (Impresso), v. 13, p. 115-126, 2014. Ambas integraram o projeto de pesquisa: Mulheres, Gêneros e Feminismos: Olhares interdisciplinares e construção de identidades (FAPESB e CAPES, 2009 a 2011). Conferir também CAVALCANTI, 2006. 
identificada apenas como M. S., de Natal (RN), 2006.

Não é possível mais inferir que as mulheres sigam

invisibilizadas en torno al fenómeno migratorio, todo lo contrario, las pesquisas han tocado aspectos medulares que han servido para la construcción de un campo de estudios que por su complejidad ha tenido que focalizar las miradas a diferentes niveles de análisis (nivel micro, meso y macro). Miradas que visibilizan a las mujeres y sus experiencias migratorias rescatando lo vivido (SMITH; GONZÁLEZ, 2015, p. 147).

As conexóes entre a temática migrações e gênero(s), especificando, neste texto, uma abordagem sobre mulheres e meninas, estão na ordem do dia, não se restringindo ao processo formal-legal, mas, sobretudo, ao tráfico para fins de exploração sexual (CAVALCANTI, 2015). São elas caracterizadas como já tendo sofrido algum tipo de violência doméstica e intrafamiliar (abuso sexual, estupro, sedução, atentado violento ao pudor, corrupção de menores, abandono, negligência, maus-tratos, dentre outros) e extrafamiliar (os mesmos e outros tipos de violência intrafamiliar, em escolas, abrigos, em redes de exploração sexual e em outras relaçóes). Os contextos familiares, pelas investigaçóes realizadas a partir dos anos 90, identificam também quadros situacionais complexos e de vulnerabilidades múltiplas (sofrem violência social, interpessoal e estrutural), "o que facilita a inserção da criança e do adolescente nas redes de comercialização do sexo, pois se tornam vulneráveis frente à fragilidade das redes protetoras (família/Estado/Sociedade)" (OIT, 2006, p. 24).

As relações entre Brasil, Portugal e Espanha, no que se refere ao tráfico, exploração e migraçóes para casamentos "arranjados", ganharam grande destaque, inclusive midiático, ressaltando tensóes diplomáticas, relaçôes de conflito e urgência em estruturar redes e agendas de políticas públicas comuns. 
No que se refere aos últimos trinta anos, todos os dados indicam uma expressiva presença feminina. $\mathrm{O}$ perfil da migração brasileira para a Espanha e para Portugal, especialmente, a comunidade em destaque é predominantemente feminina e jovem, sendo ainda item a ser assinalado o fato de serem procedentes de regióes urbanas do Brasil. Segundo as pesquisas, as brasileiras podem ser classificadas ou incorporadas em dois grandes grupos: 1) recém-chegadas e sediadas "en su mayoria en clubes, en hoteles de carretera o en pisos en grupos de dos o três, dedicadas todas ellas al alterne y la prostitución"; 2) fixadas há dois ou mais anos, seja através de convivência marital com cidadáos espanhóis (que conheceram no Brasil) ou que tenham conseguido algum emprego distinto do alterne. Nesse montante, poucas são estudantes ou mulheres na terceira idade que acompanham seus filhos.

No que diz respeito ao tráfico externo (...), na maioria dos casos, o destino das traficadas (mulheres e adolescentes) é um país europeu, em especial a Espanha. Entretanto, há um considerável número de rotas para países da América do Sul, sobretudo Guiana Francesa e Suriname, e para a Ásia (OIT, 2006, p. 45).

É interessante que o próprio informe revela que as que se casam, o fazem no Brasil após um "enamoramiento sospechosamente acelerado". Ao invés de uma formação familiar, a ideia passa a ser "sair da pobreza e ajudar os seus parentes que ficam". A partir desse ponto, gostaria de salientar a necessidade de analisar a via de mão dupla: não somente tentam deixar a pobreza através da "passagens que revelam destinos", pois não são somente prostitutas ou casamenteiras, mas também são "convidadas" e cooptadas através de redes internacionais de tráfico de pessoas e de ilusōes de um mundo muito distinto do vivido em terras longínquas.

Tal fato pode ser observado através da imprensa (que também tem papel duplo - promover e informar), não só pela própria 
informação e localização de agências de tráfico de pessoas, mas, sobretudo, pelos entrevistados titulares e manchetes - como podem ser observados alguns exemplos a seguir.

Após investigação na região da Andaluzia, uma rede de traficantes foi detida, revelando que "enganadas com falsas promessas, as mulheres entravam na Europa por Paris ou Málaga, no Sul da Espanha, e eram levadas para trabalhar em clubes sevilhanos". A maior parte foi deportada após prisão dos traficantes (BBC, 2007).

Meu sonho é sair dessa vida, encontrar um grande amor, viver tranquila. Mas quando você trabalha como prostituta você fica fria, não existe carinho, nem calor. Todo o dia recebo mais ou menos cem ligações de clientes. Escolho dois ou três... acho que não sou mais capaz de amar, mas posso pagar escola particular para meu filho, comprei uma casa para a minha mãe..., diz S.C., prostituta brasileira que trabalha em Milão (BBC Brasil, 2007).

Recaudar el suficiente dinero para comenzar una nueva vida en su ciudad de origen, con nivel socioeconómico superior, independientemente de la situación politica, económica o social de Brasil

(La mujer..., 2000).

São mulheres jovens, muitas pobres, com filhos que ficaram no Brasil, que vieram da Bahia, de Goiás, Paraná, e com um projeto de vida bem definido na cabeça: Ficar alguns anos fora e depois voltar para o Brasil para recomeçar uma vida (Daniela Rocha, oficial de projeto da OIT, BBC Brasil, 2007).

Muchas de estas mujeres son madres, pero sus hijos se quedan en Brasil, cuidados por familiares cercanos en grado, normalmente por sus abuelas. Desde aqui, en cuanto pueden, hacen envios de dinero para el mantenimiento de los suyos, que representan al menos la mitad de sus ingresos (La mujer..., 2000). 
Mencionar que essas mulheres imigrantes e jovens chegam simplesmente para ocupar lugares pouco dignos ou que em geral são considerados como informais, talvez não realmente entre no cerne da questão. No entanto, não é exclusiva a opinião de Guillermo de la Dehesa (Cf. The OECD Observer, 1995; CASTELLS, 2006), quando afirma que se o olhar é fixo sobre os incrementos também trazidos pela imigração (os dados revelam que são positivas as inserçóes tanto no crescimento do PIB, quanto de finanças públicas para os anos de 2001 a 2005), tudo estará mais vulnerável, frágil e sob uma perspectiva bastante comprometida.

En definitiva, los inmigrantes han alargado la fase expansiva del ciclo unos años más, mejorado la convergencia de PIB por habitante con la Unión Europea, retrasado casi una década el problema de financiación de las pensiones y moderado el aterrizaje de la burbuja de la vivienda, pero también, han acrecentado el abultado déficit corriente exterior de la economía española (DEHESA, 2007, p. 1).

Concomitantemente, não se pode deixar de mencionar que o processo migratório - dos países das regiões excluídas para os “oásis" de rentabilidade (KURZ, 2015) - cria um imaginário, potencializado pela ilusão de benefícios econômicos e criação de redes internacionais de tráfico de pessoas, como acaba sendo o caso da maior parte das mulheres que chegam à Espanha.

As informaçôes que circulam pela mídia - e isso foi alvo de pesquisa através da imprensa escrita espanhola e britânica de grande circulação no que se refere ao período de 1998/2005 - são reforçadas pelas "redes sociais de imigrantes" e pelo uso de novas tecnologias ${ }^{5}$. Esta é uma característica fundamental das migraçóes a

5 Para o período subsequente, os dados não são diferentes. Somente a partir de 2009, a faixa etária abaixa e configura-se predominantemente pelo grupo entre 19 e 29 anos. 
longa distância e, sem dúvida, das internacionais. Ninguém migra isoladamente: um dos motivos básicos recolhidos nas entrevistas foi a justificativa de auxiliar parentes e familiares, ou, depois da fixação confirmada e adaptação ao país de destino, a possibilidade de agrupamento familiar. $\mathrm{O}$ processo tende a ser coletivo, e a criação de redes (seja nas duas modalidades elencadas no informe da Junta de $\mathrm{CyL}$ ) promove as condiçóes do país de destino com facilidades no processo de adaptação que, não obstante, gera guetos, lócus de convivência que acaba dificultando a integração na sociedade e na economia dos países de destino. Nesse sentido, uma das linhas mestras de debates sobre multiculturalidade, integração e coesão social, no que se refere à imigração, sem dúvida, é a construção de identidades a partir de uma "cultura de passagem" (ANISTIA, 2001).

A situação de mulheres brasileiras imigrantes - com destaque para Espanha, Itália, Alemanha e Suíça - já não merece mais levantamento estatístico simplesmente. A Organização Internacional do Trabalho (OIT), no segundo semestre de 2007, com apoio do governo brasileiro, lançou o "Passaporte para a liberdade", um manual de instruçóes que auxilia brasileiras a sair da rede internacional de prostituição e que buscam a legalização de sua situação no país em que vivem.

A cartilha aconselha que a vítima denuncie seu algoz às autoridades. Em troca, ela conquistaria o direito de viver no país em que vive. Este seria, segundo os autores do documento, um incentivo a mais para quem tem filhos no Brasil, pois eles teriam direito a viver com a mãe (BBC Brasil, 2007).

Paradoxo? Seria importante ver além das fronteiras e acima das barreiras. Migraçóes, deslocamentos ou tráfico? Seria bom compreender os dois lados da fronteira (GLISSANT, 2008), os dois lados do movimento migratório (viajantes/“convidadas” e ilusionistas/traficantes/consumidores). Para tecer e tatear o detalhe da vida cotidiana das mulheres brasileiras imigrantes não se pode simples- 
mente relatar dados e impressóes às escuras. Retomamos a tese do "reconhecimento como não reconhecimento" (KURZ, 2015) para aludir que no processo migratório de mulheres há uma linha tênue entre a sua pura existência como seres humanos e, na perspectiva de sujeitos modernos de direito, como forma-mercadorias que serão submetidas ao processo de circulação e rentabilidade do capital.

A segunda atende ao procedimento de não reconhecimento consoante o valor como sujeito automático da sociedade; e a sua pura existência é posta em prova se o objetivo do reconhecimento não estiver vinculado às composiçóes ideológicas ou políticas de perpetuação da ordem vigente (leia-se estabilidade democrático-liberal). Se uma dessas mulheres migrantes não for reconhecida pelo mercado, condição sine qua non para inserção nos “oásis" de rentabilidade, sua existência assume o status de "mercadoria supérflua" e será descartada, como ser humano, da lógica econômica.

Neste contexto, a relevância do estudo teórico da dissociação-valor é comprovada ao destacar o papel do fetichismo nas relaçôes sociais de produção modernas e os limites desta mesma teoria se o objetivo não for suplantar as relaçôes patriarcais-capitalistas.

Uma teoria da dissociação-valor assim determinada, que está obrigada ao autodesmentido para poder afirmar-se, nessa medida também tem aqui de pensar contra si mesma, quando analisa náo apenas o sexismo, mas também o racismo, o antis-semitismo, o anticiganismo, a homofobia, migraçóes de meninas e mulheres e afins como dimensões próprias da discriminação social com iguais direitos (SCHOLZ, 2014, p. 1, grifo nosso).

Por conseguinte, os danos de reconhecimento, para além do superficial tratamento jurídico, estão na suposição de que a identificação política e suas instituiçóes podem engendrar uma nova plataforma migratória global, sem correspondência direta com os limites de reprodução/valorização do sistema capitalista. Perigoso equívoco presente na dualidade teoria/práxis emancipatória, pois a 
relação migração/PIB entre as regiōes excluídas e os oásis de rentabilidade, neste limiar do século XXI, recrudesce o fluxo contínuo da miséria e da concorrência pela força de trabalho barata em seus distintos campos de atuação, especialmente sobre a população feminina originária de regióes não significativas para o ordenamento mundial.

\title{
Um oceano no meio do caminho: Tratado de Amizade ou lusofonia pautada em tensóes?
}

\author{
Anda perdido no meio das caboclas \\ Mulheres que não sabem o que é pecado \\ Os santos delas são mais fortes do que os meus \\ Fazem orelhas moucas do peditório dos céus \\ Já deve estar por lá amarrado \\ Num rosário de búzios que o deixou enfeitiçado
}

Cantado por Ana Moura. Letra de Carlos Tê. O meu amor foi para o

Brasil, 2015.

Os anos entre 2009 e 2015 foram marcados por mais um estágio da crise estrutural do capital que abalou vários países, principalmente os da Península Ibérica. Manifestaçóes sociais, revogação de direitos sociais e fortes planos de austeridade, além de dívida externa, PIB em baixa, falta de investidores, desemprego e, talvez o mais grave, desesperança e apatia política. E como não poderia faltar, medida mais específica para o imigrante, conhecida como a "Diretiva da Vergonha" ou Diretiva do Retorno, adotada pela União Europeia, uma medida que expóe claramente o "direito" à hostilidade por parte das autoridades contra o imigrante ilegal. As últimas décadas foram austeras para os imigrantes, inclusive com deportaçóes e programas de incentivo ao retorno.

A incorporação na lei portuguesa constitui um retrocesso imposto pela Europa de Sarkozy e Merkel, 
[...] esta diretiva foi criticada mundialmente, inclusive por vários governos e pela Igreja Católica, como contraditória aos melhores valores civilizacionais europeus e uma flagrante violação à Dignidade da Pessoa Humana e aos Direitos Humanos (ESQUERDA. NET. $1^{\circ}$ abr. 2012).

Em momentos de crise, outro tipo de comércio tem se favorecido, mediante as "circunstâncias" de ser muito lucrativo dentro do comércio ilegal. São o tráfico e a exploração de seres humanos um grande problema no mundo, principalmente os mais afetados pela crise de valorização sem substância do capital, que impóe duras sançôes aos países que não corroboram para o processo de alimentação simulada por intermédio do crédito. Existem dois tipos de migraçóes: o primeiro é motivado pelo fator intelectual do indivíduo, pela pretensão de enriquecer culturalmente o seu conhecimento sobre lugares diferentes daquele em que nasceu e viveu grande parte de sua vida, tendo vivido até alguns períodos históricos.

O segundo é uma necessidade de sobrevivência básica, migrações motivadas por catástrofes da natureza, estaçôes climáticas ou por simples ausência de emprego, uma vulnerabilidade (econômica e, sobretudo, social). Todos são fatores aparentemente contribuintes para uma melhoria nas condiçóes de vida, seja intelectual ou por preservação da própria espécie. Porém, a questão que abrange a busca por trabalho envolve a dignidade humana, o querer aliviar a sua situação de pobreza, migrando para outro local, em casos em que o próprio Estado ao qual está subordinado lhe oferece os direitos básicos para a sua sobrevivência. Podemos observar como a crise estrutural em determinados países interfere na justiça social de uma sociedade e no bem-estar de seus cidadãos. Atualmente, a Península Ibérica vive um processo de inversão migratória, inclusive incentivada pelos próprios Estados. Até os anos 2000, o foco migratório foi ascendente. Com a crise, a partir de 2009, há uma confluência emigratória e programas de estímulo ao "retorno" para estrangeiros, muitas deportaçôes e migraçôes "forçadas". 
No decorrer da história, os migrantes sempre foram designados a trabalhos secundários em fábricas, fazendas e construçáo civil. Mas com a era da automatização robótica, fim dos anos 70 , muitos imigrantes perderam suas possibilidades de melhoria de vida, a sua força de trabalho foi trocada por uma única máquina, com capacidade de substituir dois ou mais funcionários como ele. Imigrantes tornaram-se concorrentes no banco de oportunidades para emprego nas localidades internacionais, criando inclusive revanchismos e reaçôes xenofóbicas. E para as políticas de imigraçáo, um alvo para ser contido no controle entre as fronteiras.

\begin{abstract}
A gestáo da crise capitalista em todos os países ocidentais pressiona a força de trabalho nacional a aceitar trabalhos de baixa remuneraçáo por meio de cortes e da redução do tempo do seguro-desemprego cada vez mais drásticos (...) à estrutura social da migração que ultrapassa as fronteiras a grande quantidade de força de trabalho jovem é feminina. Elas vão parar na prostituição em massa ou se tornam empregadas domésticas ou enfermeiras de clínicas ou asilos etc., onde formam um amortecedor de baixos salários para as respectivas infraestruturas arruinadas pelas condiçôes da crise (KURZ, 2015, p. 62).
\end{abstract}

A migração é um motivo de desequilíbrio, diferenças, explorações e ataques de xenofobia entre pessoas dos países desenvolvidos. Tal situação tem sido "justificada" por conta da crise econômica e instabilidade política em diversas naçóes e hoje se tornou um "mal" das sociedades desenvolvidas economicamente, pois diferente dos primórdios dos fluxos migratórios, o objetivo não é mais atender aos interesses de expansão territorial (imperialismo clássico), manter o controle e a segurança dos "oásis" de rentabilidade que são assolados por uma horda de seres humanos em busca de reconhecimento.

Para os países excluídos do ordenamento mundial, resta a gestão da barbárie por meio da forma abstrata do direito. Uma 
lacuna não cumprida, por exemplo, na Constituição brasileira de 1988, que propóe "construir uma sociedade livre, justa e solidária" (BRASIL CF, 1988, Art. 3º, Inc. I). E em Portugal, sem o apoio do governo e de instituiçóes especializadas, alguns imigrantes persistem em se debruçar sobre os "laços fracos" de uma sociedade. Vale reiterar que a valorização do valor é o seu sujeito automático. Para obter trabalho, as pessoas mantêm contato através de redes sociais informais, compostas por conhecidos, portugueses e brasileiros que vivem em Portugal. É uma rede que não apenas divulga informaçôes, oportunidades e/ou meios para conseguir empregos, mas dá orientação sobre algum local que precise de mão de obra. Obtendo a orientação, o imigrante, por si só, vai à procura do trabalho. Apesar da crise, se comparada com outros países do "terceiro mundo", há (ainda) países na Europa que correspondem a um oásis de rentabilidade e continuam a atrair, cada vez mais, a competitiva massa de seres em busca do reconhecimento pela rentabilidade.

Crise dos refugiados - esta a expressão, nos debates políticos e mediáticos a partir do segundo semestre deste ano, para referir todos os dramas por trás das pessoas que procuram refúgio na Europa. Que não há crise de refugiados, mas sim crise do capitalismo, que se expressa nas pessoas forçadas a fugir - tal facto é ignorado deliberada ou compulsivamente. A impressão imediata despertada pelas imagens - falsa imediatidade - determina a percepção (BOTTCHER, 2015, p. 1).

As imigraçôes ilegais, portanto, surgem como uma contrarresposta a essa barreira política de dificuldades impostas. Neste cenário, há o aparecimento dos "sem-papéis"6.

6 Nome dado aos imigrantes nấo regularizados que não conseguem o visto de residência. Eles conseguem o trabalho por meio de documentos falsos (comprados em euros) ou de terceiros. Existem quadrilhas especializadas em "legalizar" a situação dos imigrantes. 
O Tribunal de Instrução Criminal decretou hoje a prisão preventiva de três dos seis arguidos detidos na terça-feira numa operação do SEF que desmantelou uma rede internacional de auxílio à imigração ilegal, informou hoje o Ministério Público. [...] O grupo dedicava-se desde 2009 à legalização de imigrantes com recurso a métodos ilícitos, como a obtenção de autorizaçóes de residência através de falsos contratos de trabalho e da falsificação de documentos necessários. Aos imigrantes que recorriam a esta rede para obterem a legalização no país eram cobrados valores que podiam chegar aos oito mil euros, segundo a PGDL (EXPRESSO, 16 jun. 2011).

Pagar alto e em euros pela legalização possa ser, talvez, o mínimo de transtorno sofrido pelo imigrante. Há situaçóes em que o "legalizar" fica valendo apenas e somente como promessa:

Essa operação foi o culminar de uma investigação do $\mathrm{SEF}^{7}$ que durou mais de um ano e apurou que dezenas de mulheres passaram por esta organização, muitas delas traficadas, outras que se prostituíam por iniciativa própria mediante uma promessa de legalização em Portugal (EXPRESSO, 14 jun. 2011).

Se para os homens, a exploração é feita através da sua força de trabalho; para as mulheres, disponíveis estão esses mesmos serviços secundários e também a prostituição com ou sem a intenção

7 O Serviço de Estrangeiros e Fronteiras (SEF) é um serviço de segurança com objetivos de controlar a circulação de pessoas nas fronteiras, a permanência e atividades de estrangeiros, que pretende dar execução à política de imigração e asilo de Portugal, de acordo com as disposiçôes da Constituição e da Lei e as orientaçóes do Governo. 
da mulher imigrante, esta acaba sendo uma saída temporária para a falta de dinheiro e/ou permanência no exterior. Existe uma grande diferença entre exploração sexual e prostituição. No primeiro caso, a exploração, a vítima do tráfico se personifica quando há um aprisionamento em seu posto de "trabalho" por motivos de dívidas, violência e retenção de documentos, é a mulher - ou homem obrigada(o) a manter relaçóes sexuais com diversos homens/mulheres várias vezes ao dia, estando com sua liberdade confinada (um princípio básico de direito) e há casos em que, para aguentar a rotatividade de clientes, algumas fazem (e ou são forçadas a fazer) o uso de drogas, causando a posteriori uma dependência química, agravando ainda mais a sua condição de vítima. Destarte, a pessoa sai de sua condição de ser-humano e torna-se uma mercadoria (reconhecimento pelo não reconhecimento). No segundo caso (a prostituição), a mulher possui liberdade para escolher o horário, o tipo e a quantidade de clientes em que deseja "trabalhar". A depender do "ponto de vista", a prostituição ganha sentidos diferentes, tanto para o lado positivo, quanto negativo.

A prostituição constitui uma violação fundamental dos direitos humanos das mulheres, é uma forma de violência masculina [...] Além disso, também é um elemento importante da escravidão moderna na Europa, o tráfico humano. Se conseguirmos uma sociedade livre de prostituição e de exploração sexual de mulheres e meninas, também ficaremos livres de uma grande parte do tráfico humano na UE. (HEDH, 30 de out. 2012).

A concretização do sonho épico também está no imaginário de muitas mulheres, a busca por um marido estrangeiro que garanta sua permanência num rico país por meio de um casamento e, assim, alivie a pobreza. Podendo retornar (ou não) ao seu país de origem numa situação bem melhor, é a chamada migração eco- 
nômica (CONCEIÇÃO, 2013). O que não sabem é que podem cair num esquema de tráfico e exploração e se tornarem reféns de seus próprios anseios, como escravas sexuais. O que está contido na pobreza é o que torna um dos primeiros fatores que motivam a migração, a vulnerabilidade proveniente de motivos econômicos e sociais, gênero e etnia.

São mulheres entre 17 e 25 anos, de classe popular, baixa escolaridade e qualificação profissional, muitas possuem filhos (como mães solteiras) e/ou ajudam a família no sustento da casa (RODRIGUES, 2013, p. 1).

É no país de destino, quando o traficante se apossa de seus documentos, que ela torna-se vítima. Como estratégia dos traficantes, retirar a documentação das imigrantes faz parte do primeiro passo para assegurar a vulnerabilidade do indivíduo e garantir a subordinação perante o novo "serviço".

[...] tratando da obtenção de todo o tipo de documentos e meios necessários para a deslocação dos clandestinos, [...] Uma vez chegados ao destino, os grupos criminosos continuam a controlar a situação dos imigrantes, se necessário, através da força física e coação psicológica, [...] e de ameaças às famílias (PEIXOTO, 2005. p. 123).

Em Portugal, a prostituição se espalha por diversos locais. Em ruas dos principais centros urbanos, bares, clubes, apartamentos e até nas autoestradas ${ }^{8}$. Os preços variam conforme o ambiente e o nível intelectual das profissionais, sejam em automóveis equipados para a relação ou em casas de alternes.

8 É comum em Portugal a presença de prostitutas à espera de um programa nas beiras de estradas (regióes mais afastadas das zonas urbanas). A prostituta sente-se menos alvejada pela sociedade local, o acontecimento das "Mães de Bragança" é lembrado com repúdio por elas. Ver CASTILHOS, 2012. 
A prostituição espalha-se pelas estradas de norte a sul do País. As rectas de Coina e Pegóes, Setúbal, são muito conhecidas. Outro dos pontos é a estrada nacional na Mealhada - Próxima a Coimbra (TRIGUEIRÃO, 2009, p. 1).

Essas profissionais do sexo são mulheres solteiras ou divorciadas, entre os 21 e os 50 anos e com problemas econômicos. Já não são somente as toxicodependentes que vivem da prostituição. Muitas das jovens perderam o emprego e com a crise encontram dificuldades para se inserir no mercado de trabalho. Outras, após se separarem dos maridos, ficaram sem renda para sustentar os filhos. Mesmo sob condiçóes de escolhas, as prostitutas não estão livres da exploração e agressividade. A violência contra mulheres de programas (lenocínio) continua um problema constante, e a justiça portuguesa impôs penas duras para os acusados:

As penas entre 12 anos e sete anos e meio acabaram de ser ditadas pelo juiz Raul Cordeiro [...] As penas aplicadas pela exploraçáo violenta de prostitutas são acima do que solicitou o próprio Ministério Público durante as alegações finais (EXPRESSO. 7 out. 2011).

Em maioria, os chamados arguidos são agressores que cobram taxas de "proteção" para as prostitutas. As que não pagam, são intimidadas com ameaças de violências físicas e psicológicas ou em seus filhos. Para além das ameaças, as prostitutas estão submetidas ao risco de morte por assassinato - os requintes de crueldade são a confirmação da desumanização desta sociedade cuja forma social é representada pela forma dinheiro.

Em junho de 2012, ainda em Portugal, foi anunciada a morte de uma prostituta brasileira dentro do seu próprio apartamento, o local de "trabalho". 
Ao abrirem a porta depararam-se com a brasileira de 53 anos deitada na cama, com pés e mão amarrados, o corpo ensanguentado e a zona da cabeça carbonizada. Estava morta há várias horas. [...] O caso está a ser investigado pela secção de homicídios da Polícia Judiciária de Lisboa (RODRIGUES, 2013, p. 1).

Um estudo realizado na cidade do Porto constatou que quase metade (44\%) das prostitutas de rua que participaram da entrevista tentou o suicídio, algumas mais de uma vez; taxa mais de cem vezes superior à estimativa entre a populaçáo geral.

Atendendo a que o número de suicídios em Portugal é de 9,6 por cada 100 mil habitantes/ano e que os cientistas calculam que por cada suicídio consumado haja outras 30 tentativas, contas feitas pela Lusa levam ao número provável de 28.800 tentativas anuais no país e uma taxa de 0,28 por cento. Quando comparados, os dados recolhidos por Alexandre Teixeira indiciam uma taxa de suicídio tentado entre o universo de prostitutas inquirido mais de 170 vezes superior à estimativa do que ocorre entre a população portuguesa em geral (DIÁRIO DE NOTÍCIAS PORTUGAL. 10 set. 2011).

Em plena mundialização, regida por um sistema de valorização (sem substância) do capital, tudo o que gira em torno do lucro é tratado como mercadoria: neste caso, a força de trabalho e o corpo de alguém. $\mathrm{O}$ vício do consumismo contaminou a sociedade contemporânea, as pessoas necessitam usar e criar formas (como cliente 9 ou como patrão) de sobre-exploração do indivíduo para manter o fluxo do capital e, por conseguinte, de alocação do capital

9 "Eles combinam entre si e colocam as 'meninas' a rodar nas diferentes casas". Este sistema de 'rodízio' permite que os clientes tenham sempre caras novas. Expresso. Prostituição: Filhas de Bragança. 2008. Disponível em: <http://expresso.sapo.pt/filhas-de-braganca=f306413 \#ixzz2Bqhisqm8>. 
excedente para garantir sobrevida de um sistema que enfrenta uma contradição histórica:

\begin{abstract}
A racionalização microeletrônica pós-fordista e a globalização dos mercados de mercadorias e de trabalho e dos grandes mercados financeiros fizeram com que quantidades tão grandes de trabalho se tornassem não rentáveis, que todo o mecanismo histórico de compensação existente até agora começa a desmoronar. Em outras palavras: pela primeira vez na História, a velocidade de racionalização eliminadora de trabalho supera a expansão dos mercados. A produtividade aumenta com rapidez cada vez maior, ao passo que a expansão do modo de produção, considerada em sua totalidade, chegou ao fim (KURZ, 1997, p. 113).
\end{abstract}

Não obstante, é de grande interesse de alguns empregadores manter um funcionário imigrante porque este representa uma mão de obra barata e flexível. Começou com a escravatura e posteriormente, no que podemos notar nos dias de hoje, com o tráfico de imigrantes, e as mulheres são aliciadas para atuar no comércio sexual ilegal.

Há ainda uma interligação significativa entre o tráfico de pessoas e os processos de globalizaçáo - por um lado, melhores meios de comunicação e transporte facilitam o tráfico, e, por outro, a globalização é um dos principais motores do crescimento da indústria global da prostituição (Mameli 2002: 69), tradicionalmente o principal mercado do tráfico (PEIXOTO, 2005. p. 34).

Esse comércio de explorar pessoas para a obtenção de lucros é derivado do capitalismo, a máfia não precisou "entrar em crise econômica" para ter que praticar este "novo" crime de explorar os homens, as mulheres e crianças. A exploração é a escravidão da modernidade, é o meio mais fácil e ilícito de se obter lucros a in- 
vestimento zero, somente a custo de outrem. $\mathrm{O}$ aliciamento é feito tanto por pessoas próximas das vítimas (parentes, companheiros e amigos) quanto por estranhos, que se aproveitam da vulnerabilidade econômica e social com ofertas de emprego em casa de família, estabelecimento comercial e, até mesmo, locais específicos para as que querem se prostituir.

\begin{abstract}
Quanto aos traficantes, atuam a dois níveis, um mais organizado, com estrutura hierárquica, onde se inserem as máfias de Leste, e outro mais artesanal, constituídos por três ou quatro indivíduos, mais ligados ao tráfico de jovens brasileiras e africanas. São homens entre os 30 e 40 anos, havendo envolvimento de portugueses, que assumem o papel de donos, transportadores e seguranças, mas há também mulheres envolvidas no recrutamento, na exploração e também no controle (EXPRESSO, 7 fev. 2008).
\end{abstract}

É notável a presença de mulheres no aliciamento (cerca de 55\%, segundo a Polícia Federal do Brasil, 2011), algumas podem ser vítimas aliciadas, que para a quitação de sua dívida tenham que aliciar outras novas garotas. A intenção é sempre a mesma, de conquistar a confiança da vítima e garantir a mercadoria para o comércio. Há casos de homens que, para obter o mesmo propósito, se passam até por atenciosos namorados. As redes criminosas possuem diferentes ramos de atuação, dificultando as autoridades locais na captura e identificação dos criminosos:

Em entretenimento (como: prostíbulos, agências de acompanhantes, casas de massagem, casas de shows, danceterias, boates, bares, restaurantes, lanchonetes, motéis e barracas de praia); Agências de modelos, de emprego (para empregadas domésticas, babás, acompanhantes); de viagens (dançarinas, atrizes e cantoras); de casamento; de turismo (hotéis, spas / resorts, empresas de táxi); Em produtoras de vídeos pornográficos; Serviço de sexo virtual por telefone (OIT, 2006. p. 56). 
Os esforços necessários, ou seja, a informação precisa ser dirigida às camadas mais pobres da sociedade, oito brasileiras (dentre as 40 vítimas do tráfico sexual, 2009) foram libertadas em ação da Polícia Federal juntamente com a europeia devido a uma denúncia anônima feita por uma telespectadora, de uma novela que aborda o tema.

A maioria das mulheres exploradas sexualmente em Portugal. São jovens brasileiras e de Leste até aos 35 anos, provenientes de contextos sociais fragilizados, classes baixas e com filhos. [...] A tendência, é para as brasileiras e as de Leste serem colocadas em prostituiçáo abrigada e de luxo e as africanas e romenas nas ruas.

[...] nem todos (os agentes) são portugueses, há pessoas de etnias diferentes que usam da conveniência (e esperteza) de pertencerem à outra nacionalidade, para que seja possível, através da migração, a fuga para diversos países sem deixar rastros após efetuarem o crime de exploração (EXPRESSO. 7 fev. 2008).

Em recente estudo elaborado pela OIT (2006, p. 49), das 241 rotas do tráfico humano, 131 são internacionais e as 110 restantes estão localizadas no Brasil. Goiás, São Paulo, Minas Gerais e Rio de Janeiro são centros de origem do tráfico. Os principais destinos são Europa (ênfase na Espanha; em Portugal; na França e na Itália) e Estados Unidos.

Portugal, junto com a Espanha, tem se tornado um dos grandes países da Europa receptores deste comércio ilícito de tráfico de mulheres brasileiras. Facilitado tanto pela praticidade da comunicação quanto por acordos políticos de migração entre governos.

A entrada das cidadãs brasileiras é facilitada pelo Tratado de Amizade, Cooperação e Consulta entre a República Portuguesa e a República Federativa do Brasil, aprovado pela Resolução da Assembleia da República n. ${ }^{\circ} 83 / 2000$, de 14 de Dezembro, que no ar- 
tigo $7 .^{\circ}$ estabelece a isenção de visto para cidadãos portugueses e brasileiros para estadas com fins culturais, empresariais, jornalísticos ou turísticos não superiores há três meses (SANTOS, 2007, p. 68).

\title{
Portas abertas: Migraçóes como temas quentes e urgentes
}

\begin{abstract}
$\mathrm{O}$ que queremos? O que podemos? Através da educação para e pelos Direitos Humanos conhecer, promover e difundir princípios de ordenamento social contemporâneo podem ser desafios utópicos e inalcansáveis (CAVALCANTI; SILVA, 2016, p. 120).
\end{abstract}

Vivenciamos, nos últimos quinze anos, processos cada vez mais intensos e paradoxais: as migraçóes e o tráfico de seres humanos têm suscitado uma chamada a promover, debater, colocar nas agendas (em seus múltiplos âmbitos) e tomar como ético o princípio da mobilidade e das chamadas "expressóes de Humanidade" (CAVALCANTI; SILVA, 2015). Livre circulação e construçóes relacionais multiculturais estão cada vez mais em voga. No entanto, e como contraste profundo nas relaçóes de identidade e de alteridade, temos o outro lado: violaçóes de direitos humanos em consonância com o reconhecimento de sujeitos rentáveis sob os auspícios da forma mercadoria.

Corroboramos com a Teoria Crítica (dissociação valor e fetichismo) de que para compreender o atual estágio da crise estrutural do capital e suas consequentes migraçóes em massa - das regióes excluídas para os "oásis" de rentabilidade - é fundamental abarcar os nexos causais deste fluxo migratório com os limites históricos do moderno sistema reprodutor de mercadorias em um contexto dialético negativo (ADORNO, 2003). Sem uma conscientização emancipatória, para além do espaço tradicional do fazer política e constituir suas instituiçóes, qualquer busca por reconhecimento 
será apenas mais uma comprovação do status de cidadão rentável, mas desprovido de humanidade. Ou seja, as migraçóes podem ser movimentos sociais de conscientização de que a capacidade de absorção de trabalho em grande escala está se exaurindo e que "tais processos são o resultado do

patriarcado produtor de mercadorias em desmoronamento, o qual agora também atinge historicamente os limites da sua capacidade de reprodução, em consequência da perda já náo compensável de trabalho criador de mais-valia (BOTTCHER apud SCHOLZ, 2014, p. 1).

Ademais, no sistema migratório informal e no tráfico, observase o acréscimo de itens inegáveis de não acesso à cidadania e à justiça, fortalecendo elementos de vulnerabilidade também para os países inseridos: corrupção do sistema político, desestabilização demográfica, violaçóes de Direitos Humanos e acordos internacionais ratificados pelos Estados-membro, ocupação de maiores espaços e atuação extrema de organizaçóes mafiosas, desestabilização dos mercados de trabalhos ilegais, problemas diplomáticos e de relaçóes internacionais, etc.

Parafraseando Mirbeau (2000), se não há mais um Balzac para nos elucidar a fisiologia do ser humano emancipado, seremos responsáveis pela realização de nosso próprio devir histórico, (re) elaborando o passado para compreender o nosso presente.

Se a história é aberta, se o "novo" e possível, é porque o futuro não e conhecido antecipadamente; o futuro não é o resultado inevitável de uma evolução histórica dada, o produto necessário e previsível de leis "naturais" da transformação social, fruto inevitável do progresso econômico, técnico e científico - ou o que é pior, o prolongamento, sob formas cada vez mais aperfeiçoadas, do mesmo, do que já existe, da modernidade realmente existente, das estruturas econômicas e sociais atuais (...) Afinal, a variante histórica que triunfou não era a única existente (LOWY, 2005, p. 149 e 157). 


\section{Referências}

Bahia está na rota do tráfico de pessoas. A Tarde (Bahia), Salvador, 16 de out. 2012. Disponível em:<http://atarde.uol.com.br/bahia/materias/ 1460754-bahia-esta-na-rota-do-trafico-de-pessoas $>$. Acesso em: 9 nov. 2015.

ADORNO, Theodor W. Educação e emancipaçáo. Rio de Janeiro: Paz e Terra, 2003.

ANISTIA INTERNACIONAL. Broken Bodies, Shattered Minds. Torture and Ill-Treatment of Women. London: AI, 2001.

APAV, Associação Portuguesa de Apoio à Vítima. Direitos Europeus das Vítimas. Disponível em: <http://apav.pt/apav_v2/index.php/pt/avitima-e-a-lei/direitos-europeus dasvitimas\#direitosdavitimanoprocessopenal>. Acesso em: 7 nov. 2015.

\section{BBC BRASIL. OIT lança cartilha para prostitutas brasileiras na}

Europa. Disponível em: <http://noticias.uol.com.br/bbc/reporter/2007/09/26/ult4904u190.jhtm>. Acesso em: 26 set. 2007.

BOTTCHER, Herbert. A necessidade de ação. Carta aberta às pessoas interessadas na EXIT!. Disponível em: <http://obeco.no.sapo.pt/herbert_bottcher.htm>. Acesso em: 29 jan. 2016.

BUCHSER, Corinne. "Estar sem papéis é como viver em uma prisão". In: Swissinfo. 20 de Dez. 2010. Disponível em: <http://www.swissinfo. ch /por/sociedade/Estarsempapeis_e_comoviverem\%20uma_prisao. html?cid=29050242>. Acesso em: 17 de fev. 2016

CASTELLS, Manuel. Observatório global - cronicas de principios de siglo. Espanha: La Vanguardia Ediciones, 2006.

CASTILHOS, Daniela Serra. Mulheres imigrantes em Portugal: Discurso normativo e mediático. Salamanca: Ediciones de la Universidad de Salamanca, 2012. (Colección Vítor, 326). 
CAVALCANTI, Vanessa Ribeiro Simon; SILVA, Antonio Carlos da. Em tempos incertos e emergências sociais: Para um crítica da ética, Instituiçóes e Direitos Humanos no Brasil. Anais... Coimbra: Faculdade de Economia, Centro de Estudos Sociais da Universidade de Coimbra, janeiro de 2016.

CAVALCANTI, Vanessa Ribeiro Simon; SILVA, Antonio Carlos da. Entre mundos y discursos en apoyo a los derechos humanos: enlaces, agendas y redes. In: QUINTEIRO, M.E.M; BALLESTEROS, M.P.P. (Orgs). Derechos Humanos: Pasado y Presente. Salamanca: Editorial Dykinsonaunque, 2016.

CAVALCANTI, Vanessa Ribeiro Simon; SILVA, Antonio Carlos da. Para e pelos Direitos Humanos: perspectivas e debates sobre violência, educação e agendas. In: GOMES, Celma Borges (Org.). Violência nas escolas: em busca de uma cultura da não violência. Curitiba: CRV, 2015, p. 113-122.

CAVALCANTI, Vanessa Ribeiro Simon. Cuerpos femininos y territórios de identidades: representaciones de mujeres brasileñas. In: LANARI, María Estela; HASANBEGOVIC, Claudia (Orgs.). Mujeres de Latinoamerica: el presente en vientidós letras. Buenos Aires: EUDEM, 2015, p. 129-154.

CAVALCANTI, Vanessa Ribeiro Simon. Mapeando algumas rotas internacionais (in)visíveis: História imediata, tráfico de mulheres e mídia. Projeto História (PUCSP), São Paulo, v. 31, n. 31, p. 1-17, 2006.

CNAI (Centro Nacional de Apoio ao Imigrante). Disponível em: $<$ http://www.acidi.gov.pt/es-imigrante/servicos/centros-nacionais-de-apoio-ao-imigrante---cnai>. Acesso em: 22 out. 2015

COHEN, Aaron. Portugal não cumpre os padróes mínimos. In: Expresso, 27 de Jan. 2011. Disponível em:< http://expresso.sapo.pt/portugalnao-cumpre-os-padroes-minimos $=\mathrm{f} 628582 \#$ ixzz2BCVG6Srs $>$. Acesso em: 11 nov. 2015. 
CONCEIÇÃO, Ana Manuela Santos e CAVALCANTI, Vanessa. Brasileiras em Portugal no proceso exploratório de migração sexual.Científico. Vol 13, n. 26, jul-dez 2013.

DEHESA, Guillermo de La. ¿Qué está aportando la inmigración a la economía?In. El País. Madri, Junho/2007.

DN PORTUGAL. Prostitutas são as pessoas que mais tentam suicidar-se. 10 set. 2011. Disponível em:<http://www.dn.pt/inicio/portugal/interior. aspx? contentid $=1987114 \&$ seccao $=$ Norte $>$. Acesso em: 11 nov. 2015.

ESQUERDA. NET: Associaçōes contra nova lei de imigração. $1^{\circ}$ abr. 2012. Disponível em: <http://www.esquerda.net/artigo/associa\%C3\%A7\%C3\%B5es-contra-nova-lei-de-imigracao\%C3\%A7\%C3\%A3o/22571>. Acesso em: 7 fev. 2016.

EXPRESSO, 2008. Estudos Sociais da Universidade de Coimbra. Tráfico de Mulheres em Portugal para exploração sexual. Disponível em: $<$ http://expresso.sapo.pt/coimbra-mulheres-exploradas-sexualmente-em-portugal-sao-maioritariamente-brasileiras-e-de-leste=f236329\#ixzz2B C7IBGGm>. Acesso em: 3 nov. 2015.

EXPRESSO, 2008. Mulheres exploradas sexualmente em Portugal são maioritariamente brasileiras e de Leste. 7 fev. 2008. Disponível em: $<$ http://expresso.sapo.pt/coimbra-mulheres-exploradas-sexualmente-em-portugal-sao-maioritariamente-brasileiras-e-de-leste=f236329\#ixzz2BUjvTM7P>. Acesso em: 6 nov. 2015.

EXPRESSO, 2008. Prostituição: Filhas de Bragança. 28 abr. 2008. Disponível em: <http://expresso.sapo.pt/filhas-de-braganca=f306413\#ixzz2Bqhisqm8>. Acesso em: 10 nov. 2015.

EXPRESSO, 2011. Pena recorde por explorarem prostitutas com violência. 7 de Out. 2011. Disponível em: <http://expresso.sapo.pt/penas-recorde-por-explorarem-prostitutas -com-violencia $=f 678866 \#$ ixzz $2 \mathrm{BvB}$ x7KEy>. Acesso em: 11 nov. 2015. 
EXPRESSO. SEF desmantela rede internacional de auxílio à imigração ilegal. 14 jun. 2011. Disponível em <http://expresso.sapo.pt/sef-desmantela-rede-internacional-de-auxilio-a-imigracao-ilegal=f655537\#ixzz2Az2Yud9p>. Acesso em: $1^{\circ}$ nov. 2015.

G1 (Mundo). Contra a crise econômica, Portugal corta quatro feriados nacionais. Disponível em: <http://g1.globo.com/mundo/noticia/2012/05/contra-crise-economica-portugal-corta-quatro-feriados-nacio nais.html>. Acesso em: 18 out. 2015.

GLISSANT, Edouard. Não há fronteira que não se ultrapasse. Le Monde Diplomatique, out. 2008.

HEDH, Anna.In: MCKENZIE, A. D. Imigrantes prisioneiras do comércio sexual europeu. Agência de Notícias.inter press service: Paris, 2012

JAPPE, Anselm. Crédito a norte. A decomposição do capitalismo e suas críticas. São Paulo: Hedra, 2013.

KURZ, Robert. Os paradoxos dos Direitos Humanos: inclusão e exclusão na modernidade. Disponível em: <http://obeco.planetaclix.pt/ rkurz116.htm>. Acesso em: 16 mar. 2003.

KURZ, Robert. Os últimos combates. Petrópolis: Vozes, 1997.

KURZ, Robert. Poder mundial e dinheiro mundial. Crônicas do capitalismo em declínio. Rio de Janeiro: Consequência, 2015.

LA MUJER INMIGRANTE EN CASTILLA Y LEÓN. Salamanca, Junta de Castilla y León, 2000 (Colección Mujer e Igualdad - Série Argumentos)

LOWY, Michael. Benjamin: aviso de incêndio. Uma leitura das teses sobre o conceito de história. São Paulo: Boitempo, 2005.

MASSAD, Anselmo. Rumo à barbárie (entrevista Robert Kurz). Revista FORUM, n. 24, 2009. Disponível em: <http://obeco.planetaclix.pt/ rkurz193.htm>. Acesso em: $1^{\circ}$ fev. 2016. 
MATIAS, Gonçalo. Migraçóes e cidadania. Lisboa: Fundação Francisco Manuel dos Santos, 2014.

MÉSZÁROS, István. Da Montanha que devemos conquistar. São Paulo: Boitempo, 2015.

MIRBEAU, Octave.L'abbe Jules. In vol 1of Oeuvre romanesque. Paris:Buchet/Chastel 2000.

OIT- Organização Internacional do Trabalho. Tráfico de pessoas para fins de exploração sexual. Brasília: 2006. 80 p. Disponível em: <http:// www.oitbrasil.org.br/node/384>. Acesso em: 26 fev. 2016.

PEIXOTO, João. O Tráfico de Migrantes para Portugal: Perspectivas Sociológicas, Jurídicas e Políticas. Lisboa: ACIME, Observatório da Migração, 2005.

PÚBLICO P (Economia): Metas do défice foram aliviadas, mas Governo lança mais austeridade. 2012. Disponível em: < http://www.publico. $\mathrm{pt} /$ economia/noticia/metas-do-defice-foram-aliviadas-mas-governo-lanca-mais-austeridade-1562662l>. Acesso em: 14 fev. 2016.

RODRIGUES, João; SILVA, Carolina Ana. Prostituta torturada e queimada em casa. Correio da Manhã. Porto, Portugal. 16 jun. 2012. Disponível em: <>. Acesso em: 12 nov. 2015.

RODRIGUES, Roney. Sonho de melhorar de vida faz brasileiras escravas sexuais na Europa. Caros Amigos (Cotidiano). 5 fev. 2013.

SALES, Teresa. Novos fluxos migratórios da população brasileira. Revista Brasileira de Estudos de Populaçáo, v. 8 , n. 1-2, p. 21-32, jan/dez. 1991.

SANTOS, Boaventura de Sousa; GOMES, Conceição; DUARTE, Madalena. Tráfico sexual de mulheres: representaçôes sobre ilegalidade e vitimação. Revista Crítica de Ciências Sociais, 87, Coimbra, dez. 2009. 
SANTOS, Boaventura de Sousa; GOMES, Conceição; DUARTE, Madalena; BAGANHA, Maria. (Coord.). Tráfico de Mulheres em Portugal para Fins de Exploraçáo Sexual. Coimbra: CIDM, Disponível em: <http://www.ieei.com.pt/ traficodepessoas/images/documentos/ traficodemulheresces.pdf>. Acesso em: 7 nov. 2014.

SCHOLZ, Roswitha. Após Postone (2014). Sobre a necessidade de transformação da "crítica do valor fundamental". Moishe Postone e Robert Kurz em comparação a crítica da dissociação-valor (Tradução Boaventura Antunes). Disponível em <http://obeco.no.sapo.pt/roswitha\%20scholz19.htm>. Acesso em: 29 jan. 2016.

SILVA, Antonio Carlos da. República Tupiniquim: os fins justificam os meios na condução da Política Econômica Brasileira?. EnRed - Revista Digital da Universidad de Salamanca, v. 2, n. 2, 2008.

SMITH, Yamile Delgado; GONZÁLEZ, Maria Cristina. Género y migración: desandando caminhos. Ex æquo, n. 31, p. 143-157. 2015.

The OECD Observer, n. 192, fev/mar, 1995.

TRIGUEIRÃO, Sónia. Crise atira portuguesas para as estradas. Correio da Manhã (Atualidade). Porto, Portugal, 14 de jun. 2009. Disponível em:< http://www.cmjornal.xl.pt/noticia.aspx?channelid=00000009-0000-0000-0000-000000 000009\&contenti$\mathrm{d}=\mathrm{B} 461337 \mathrm{~A}-57 \mathrm{C} 3-4 \mathrm{ED} 9-84 \mathrm{~F} 2-\mathrm{D} 4 \mathrm{~A} 8 \mathrm{DEF} 39 \mathrm{D} 7>$. Acesso em: 10 nov. 2015.

USSIA, Alfonso. El Lago de la Carne. Madrid: ABC, 2001. 